\title{
Protesa Mata: Rehabilitasi Pasien
}

\author{
Arief Waskitho*, Erwan Sugiatno**, dan Titik Ismiyati* \\ *Program Studi Prostodonsia, PPDGS Fakultas Kedokteran Gigi Universitas Gadjah Mada \\ **Bagian Prostodonsia Fakultas Kedokteran Gigi Universitas Gadjah Mada \\ *Sekip Utara No 1 Yogyakarta, e-mail: commando_dentist@yahoo.com
}

\begin{abstract}
ABSTRAK
Kasus kehilangan bola mata dapat menimbulkan masalah fungsi, psikis, dan estetik. Salah satu perawatan rehabilitatif pada kasus ini adalah dengan protesa mata. Tujuan pembuatan protesa mata adalah untuk mempercepat penyembuhan fisik dan psikis serta memperbaiki estetik. Pasien laki-laki usia 50 tahun datang ke klinik Prostodonsia RSGM Prof. Soedomo FKC UGM dengan kondisi kehilangan mata sebelah kanan akibat trauma 3 tahun yang lalu.Pemeriksaan soket mata menunjukkan konjungtiva yang sehat dan tidak terdapat infeksi. Rencana perawatan adalah pembuatan protesa mata non fabricated berbahan resin akrilik. Prosedur perawatan dilakukan dengan tahap-tahap yaitu pencetakan mata dengan sendok cetak mata perorangan dan pengisian hasil cetakan dilakukan 2 tahap. Pembuatan model malam sklera, mencoba pola malam sklera, membuat sklera akrilik, mencoba sklera akrilik, dan penentuan lokasi dan diameter iris, melukis iris dan pupil, penyelesaian protesa mata, serta insersi protesa mata, pemeriksaan yang perlu dilakukan adalah retensi, stabilisasi, dan kenyamanan protesa mata. Kontrol setelah 1 minggu protesa mata menunjukkan hasil yang baik, tidak ada keluhan rasa sakit, dan tidak ada peradangan. Pasien lebih percaya diri dan nyaman dengan protesa mata ini karena bentuknya sesuai soket mata. Pemakaian protesa mata dapat meningkatkan kepercayaan diri pasien sehingga dapat diterima dalam kehidupan sosial bermasyarakat. Maj Ked Gi; Desember 2013; 20(2): 178-183.
\end{abstract}

Kata Kunci : luka trauma, soket mata, protesa mata non fabricated

\begin{abstract}
Ocular Prosthesis: Patient Rehabilitation. The loss of eyeballs may lead to problems in function, psychology, and aesthetics. One of rehabilitative treatments for this case is by making prosthesis eyes. The purpose of this treatment is to heal the physical and psychological function quickly and to fix the aesthetics. A 50-year-old male patient who came to RSGM Prof. Soedomo FKG UGM's Prostodontia Clinic complained that he lost his right eye because of traumatic injury 3 years ago. After checking the eye socket up, it was found that his conjunctiva lining was healthy, and there was no infection. The treatment plan was to make nonfabricated ocular prosthesis from acrylic resin. For the treatment procedure, the steps are as follow: minting the individual eye by using minted spoon and pouring the minting result of the eye by two phases; making the model of wax sclera followed by trying on the wax sclera pattern to the patient eye socket and making an acrylic version of sclera followed by trying on the acrylic sclera to the eye socket, and then determining the location and iris diameter to draw the iris and pupil. The finishing process of the eye prosthesis is by inserting the eye prosthesis to the patient eye socket. The checkup is needed to know the retention, stabilization and fitting the eye prosthesis. After medical check-up during a week, the eye prosthesis showed the good result, absence of pain and inflammation. The patient was more confident psychologically and comfortable using this eye prosthesis because the shape was compatible with the eye socket. Using eye prosthesis can improve the patients' confidence as they can be accepted in social life. Maj Ked Gi; Desember 2013; 20(2): 178-183.
\end{abstract}

Key words : traumatic injury, eye socket, non-fabricated ocular prosthesis

\section{PENDAHULUAN}

Mata merupakan organ yang sangat penting untuk melihat dan ekspresi wajah. Secara anatomi mata mempunyai bagian-bagian yang terdiri dari : 1) Sklera yaitu bagian dari bola mata yang membentuk warna putih mata dan bersambung pada bagian depan dengan sebuah membran yang bening yaitu kornea. Di tengah-tengahnya terdapat iris, pupil, dan limbus serta collarate, maupun pembuluh darah. 2) Pupil yaitu suatu lingkaran kecil yang terdapat di tengah- tengah di dalam iris yang disebut juga sebagai manik mata, berwarna lebih gelap dibandingkan dengan iris. 3) Iris yaitu selaput pelangi dengan warna lebih muda dari pupil dan mempunyai garis-garis halus. 4) Limbus merupakan lapisan terluar dari iris. 5) Collarate adalah lapisan di sekitar pupil, memberikan gambaran di sekitar pupil sehingga iris lebih terlihat bersinar. 6) Otot penggerak mata terdiri dari otot lurus dan otot serong. Otot lurus adalah otot rektus mata superior, otot rektus mata inferior, otot rektus 


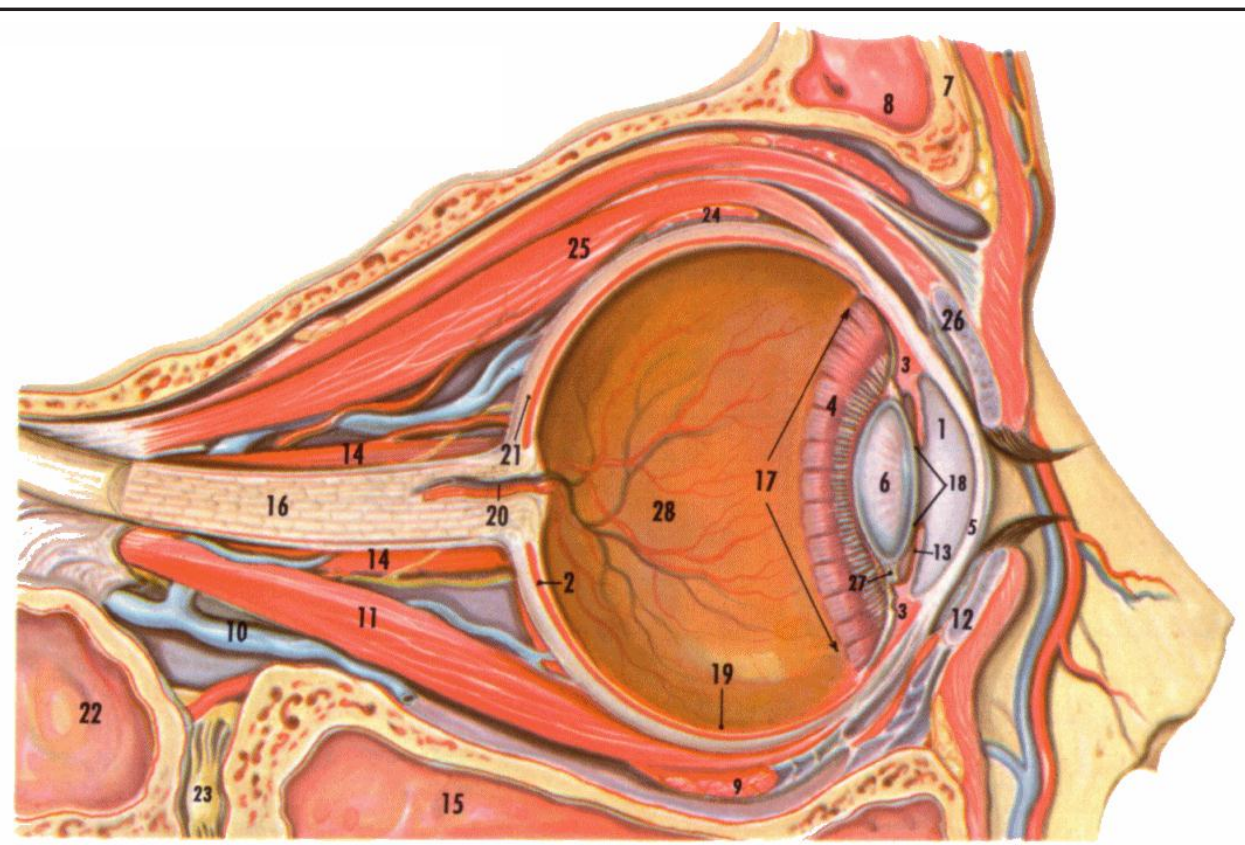
1. Aqueous chamber
2. Choroid
3. Ciliary muscle
4. Ciliary processes
5. Cornea
6. Crystalline lens
7. Frontal bone
8. Frontal sinus
9. Inferior oblique muscle
10. Inferior ophthalmic vein
11. Inferior rectus muscle
12. Inferior tarsus
13. Iris
14. Lateral rectus muscle

15. Maxillary sinus

16. Optic nerve

17. Ora serrata

18. Pupil of the iris

19. Retina

20. Retinal artery and vein

21. Sclera
22. Sphenoid sinus

23. Pterygopalatine ganglion

24. Superior oblique muscle

25. Superior rectus muscle

26. Superior tarsus

27. Suspensory ligament

28. Vitreous chamber

Gambar 1. Anatomi Mata (www.somsville.wordpress.com/15-06-2013)

mata medial, dan otot rektus mata lateral. Otot-otot lurus menggerakkan mata ke atas, bawah, dalam, dan luar secara bergantian. Otot serong adalah otot oblik inferior dan otot oblik superior. Otot oblik superior menggerakkan mata ke bawah dan ke luar. Otot oblik inferior menggerakkan mata ke atas dan ke luar'.

Pengeluaran benda asing akibat trauma pada mata ada 2, pertama adalah bedah eviserasi merupakan tindakan mengeluarkan isi bola mata saja atau pengambilan isi orbita karena kebutaan, trauma dan penyakit mata. Tindakan bedah tersebut mengeluarkan isi bola mata saja, tanpa menghilangkan sklera, konjungtiva, otot-otot mata dan syaraf mata. Kedua adalah bedah enukleasi, pengeluaran seluruh bola mata bersama sklera dengan cara menggunting otot penggerak mata dan saraf optik.Indikasi dari bedah enukleasi dan eviserasi adalah keganasan intraokular, kebutaan, nyeri mata, trauma, dan infeksi. Prosedur bedah enukleasi akan mempermudah pembuatan protesa mata karena soket mata setelah bedah enukleasi lebih dalam dibandingkan soket mata setelah bedah eviserasi. Soket mata setelah bedah eviserasi menyebabkan protesa mata lebih mudah keluar dibandingkan soket mata setelah bedah enukleasi. ${ }^{2}$

Kehilangan dari bola mata adalah sebuah proses yang sangat traumatik dalam kehidupan seorang manusia. Kewajiban dari tenaga medis adalah merehabilitasi kelainan tersebutuntuk mempercepat penyembuhan fisik dan psikis serta

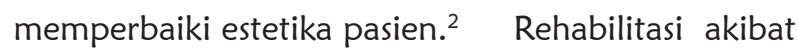
kehilangan bola mata dapat dibagi menjadi 2 jenis, yaitu implan orbital dan protesa mata. Protesa mata dibagi menjadi 2 yaitu fabricated dan non fabricated. Keuntungan dari protesa mata fabricated adalah waktu pembuatannya yang minimal karena tidak memerlukan tahapan pembuatan di laboratorium. Protesa mata fabricated erdiri dari 3 jenis ukuran dan warna iris. Kerugian protesa mata 
ini adalah ketidaknyamanan dan infeksi karena adanya perbedaan ukuran antara bola mata dan soketnya sehingga timbul kantung air yang menjadi tempat berkembangnya bakteri. Kerugian lainnya adalah ketidaksesuaian warna iris menyebabkan permasalahan estetik. ${ }^{3}$

Protesa mata yang dibuat sendiri dikenal sebagai protesa mata non fabricated. Keuntungan protesa mata non fabricated adalah warna protesa mata dapat disesuaikan dengan mata yang masih ada, harga lebih ekonomis dan sesuai dengan kondisi soket mata pasien. Kerugian dari protesa mata non fabricated adalah pembuatan protesa memerlukan waktu untuk proses laboratorium. Indikasi protesa mata non fabricated adalah setelah bedah eviscerasi dan enukleasi. Kontra indikasi protesa mata non fabricated adalah pasien yang alergi terhadap bahan akrilik dan soket mata yang kurang retensi ${ }^{4}$. Tujuan dari artikel ini adalah untuk memaparkan perawatan yang rehabilitation dengan Ocular Prosthesis.

\section{STUDI KASUS}

Pasien laki-laki usia 50 tahun datang ke klinik Prostodonsia RSCM Prof. Soedomo FKG UGM dalam kondisi kehilangan mata sebelah kanan akibat trauma 3 tahun yang lalu (Gambar 2). Riwayat kasus ini adalah trauma benda tumpul pada bola mata. Trauma terjadi karena pasien mencoba melepas bola matanya. Tindakan ini dilakukan karena sakit yang berlebihan pada bola mata serta terdapat kecenderungan di bawah pengaruh minuman keras. Pasien dirawat di rumah sakit setelah kejadian tersebut. Perawatan dilakukan dengan pengambilan bola mata yang dilanjutkan perawatan pada kantung mata sampai sembuh. Akan tetapi tidak ada rehabilitasi lanjutan dengan protesa mata setelah operasi pengambilan bola mata sehingga kantung mata sedikit mengecil.

Pada pemeriksaan obyektif terlihat kantung mata agak mengecil, tidak terdapat iritasi, dan tidak terdapat infeksi. Kelopak mata agak menegang akibat terlalu lama tanpa rehabilitasi. Otot kelopak mata masih baik sehingga bisa membuka dan menutup. Kantung mata cukup dalam sehingga masih memungkinkan untuk retensi protesa mata.
Berdasarkan anamnesis dan pemeriksaan obyektif maka dapat disimpulkan bahwa pasien mengalami kehilangan bulbus oculi dextra akibat trauma. Rencana perawatan pada pasien yang mengalami kehilangan bulbus oculi dextra akibat traumaadalah pembuatan protesa mata non fabricated dengan bahan resin akrilik6.

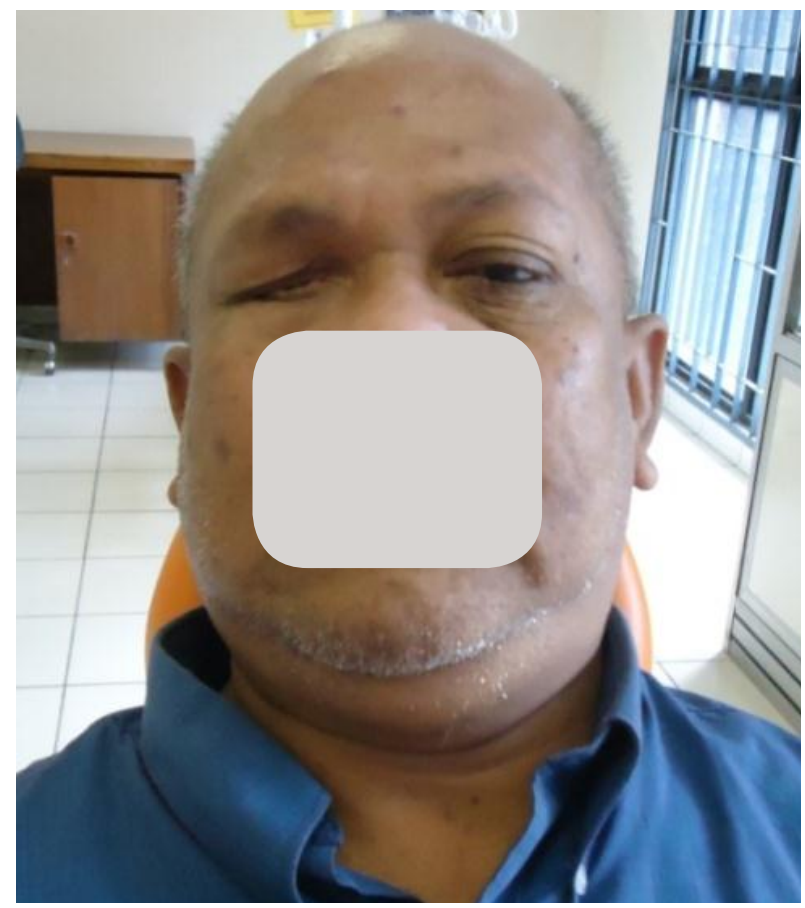

Gambar 2. Foto pasien

Kunjungan pertama dilakukan anamnesis dan pemeriksaan obyektif sehingga didapatkan diagnosis kehilangan bulbus oculi dextra akibat trauma. Rencana perawatan adalah pembuatan protesa mata non fabricated dengan bahan resin akrilik. Langkah berikutnya adalah pembuatansendok cetak dengan malam ukuran $3 \times 5 \mathrm{~cm}$ yang dilunakkan dan ditekan perlahan pada mata, kemudian diisi dengan gips. Gips yang sudah mengeras kemudian digunakan sebagai model kerja pembuatan sendok cetak mata perorangan dengan menggunakan resin akrilik self cure $^{5}$.

Kunjungan kedua adalah pencetakan mata dengan sendok cetak mata perorangan menggunakanbahan cetak silicon double impression untuk keperluan model studi dan model kerja. Metode pencetakan menggunakan metode mukostatik. Prosedur pencetakan yaitu soket mata 
diolesi dengan vaselin dan bahan cetak dimasukkan dalam spuit injeksi 10 cc. Perlahan-lahan bahan cetak diinjeksikan ke dalam soket mata (Gambar 3). Sendok cetak mata perorangan yang telah dilapisi dengan bahan cetakputty dan wash diletakkan diatas kelopak mata dan ditunggu sampai mengeras (Gambar 4). Bahan cetak yang ada di dalam dan di luar kelopak mata akan menjadi satu sehingga dapat dilepas sekaligus. Periksa hasil cetakan dan kondisi soket mata. Hindari adanya bahan cetak yang tertinggal pada soket mata. Lalu dilakukan pengisian hasil cetakan dengan bahan stone gips. Hasil cetakan dikirim ke laboratorium untuk dibuatkan model malam sclera (gambar 5). ${ }^{5}$
Kunjungan ketiga adalah mencoba pola malam yang telah dihaluskan pada pasien. Pasien diinstruksikan duduk tegak lurus dan rileks. Kelopak mata atas diangkat dan tepi atas dari pola malam sklera dimasukkan. Kelopak mata bawah ditarik sehingga tepi bawah dari pola malam dapat dimasukkan. Pola malam sklera harus nyaman sehingga tidak menyebabkan iritasi. Gerakan membuka dan menutup kelopak mata serta bentuk bola mata diperhatikan dari segala arah sehingga menyerupai mata sebelahnya.Selanjutnya dilakukan pencatatan warna sklera menggunakanfotografi mata asli pasien. Pola malam sklera yang sudah

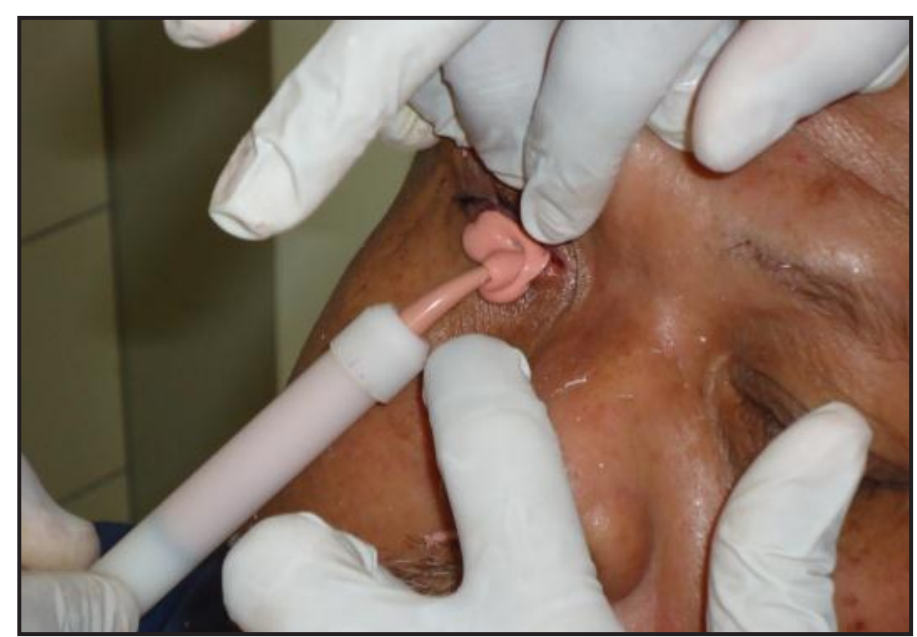

Gambar 3. Proses Pencetakan dengan spuit injeksi

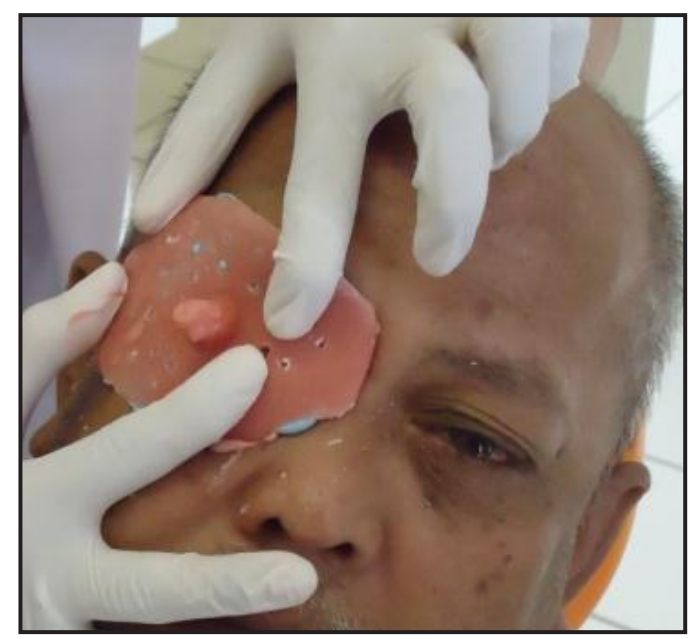

Gambar 4. Proses pencetakan dengan sendok cetak individual

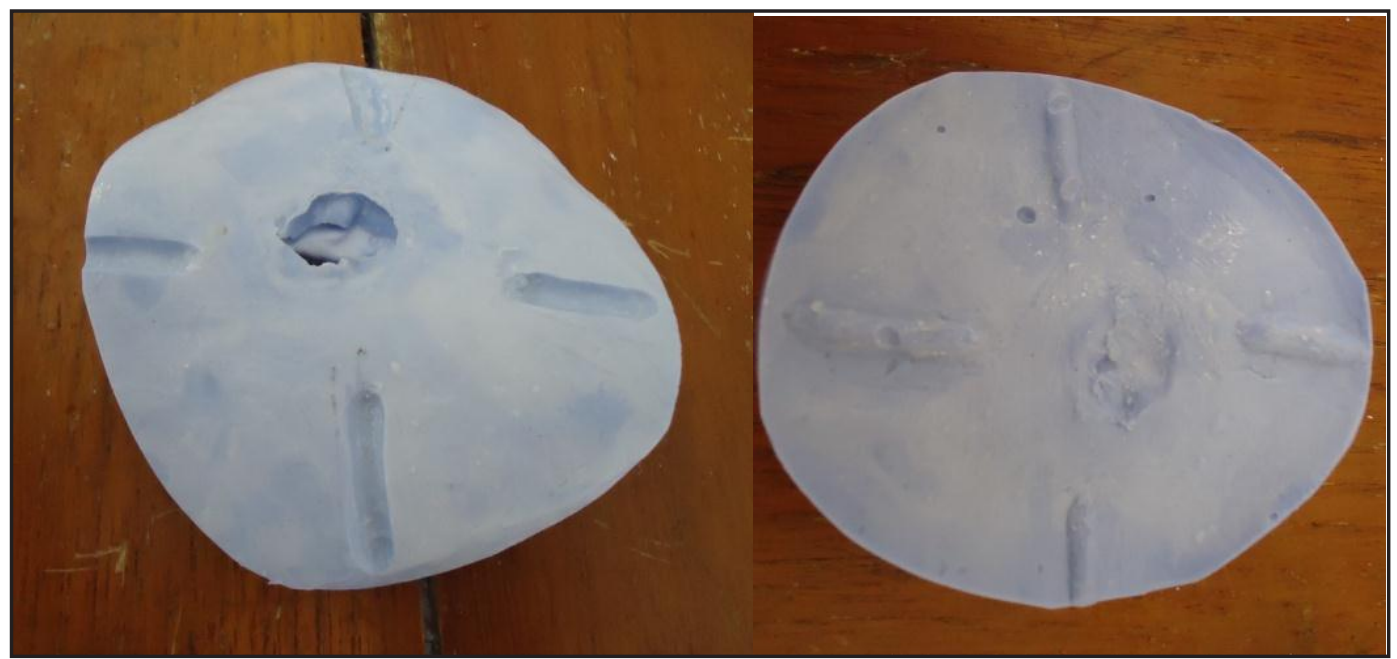

Gambar 5. Model Kerja 
dihaluskan dan catatan warna sklera dikirim ke laboratorium untuk dilakukan packing. ${ }^{5}$

Kunjungan keempat adalah mencoba sklera akrilik (Gambar 6). Pasien diinstruksikan duduk tegak lurus dan rileks. Kelopak mata atas diangkat dan tepi atas dari sklera dimasukkan. Kemudian kelopak mata bawah agak ditarik sehingga batas bagian bawah dari sklera akrilik dapat dimasukkan. Sklera akrilik harus nyaman dan tidak terdapat keluhan rasa sakit. Sklera harus simetris dengan mata sebelahnya. Pada kunjungan ini lokasi dan diameter iris serta tanda sentral pupil dibuat berdasarkan mata sebelahnya. Sentral pupil diberi tanda dengan pensil atau spidol. Sklera dilepas dari soket mata kemudian dengan jangka dibuat lingkaran yang berpusat pada tanda tersebut. Penentuan lokasi dan diameter iris disesuaikan dengan mata asli. Diameter iris biasanya berkisar antara $10 \mathrm{~mm}, 10,5 \mathrm{~mm}, 11 \mathrm{~mm}, 11,5 \mathrm{~mm}$, atau $12 \mathrm{~mm}$. Diameter iris dipastikan dengan pengukuran langsung menggunakan Sliding Caliper.Tahapan selajutnya adalah pengiriman ke laboratorium untuk pembuatan iris. ${ }^{5}$

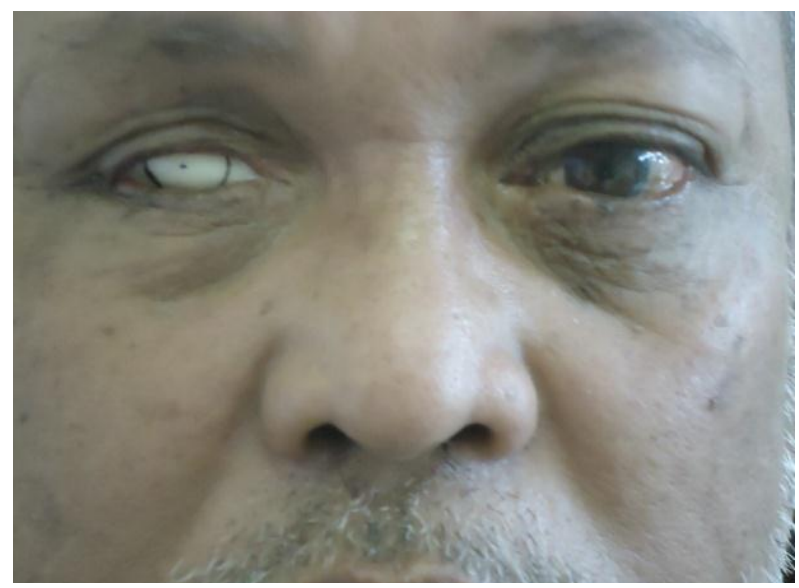

Gambar 6. Try in sklera dan penetuan posisi iris

Kunjungan kelima adalah insersi protesa mata (Gambar 7). Kelopak mata atas dan bawah dibuka secara bersamaan untuk memasukkan protesa mata. Pemeriksaan yang perlu dilakukan adalah retensi, stabilisasi, dan kenyamanan protesa mata. ${ }^{5}$

Kunjungan keenam adalah kontrol pertama setelah insersi protesa mata. Kontrol dan evaluasi perubahan soket pada pemakaian protesa mata nonfabricated dilakukan 1 minggu setelah insersi. ${ }^{5}$

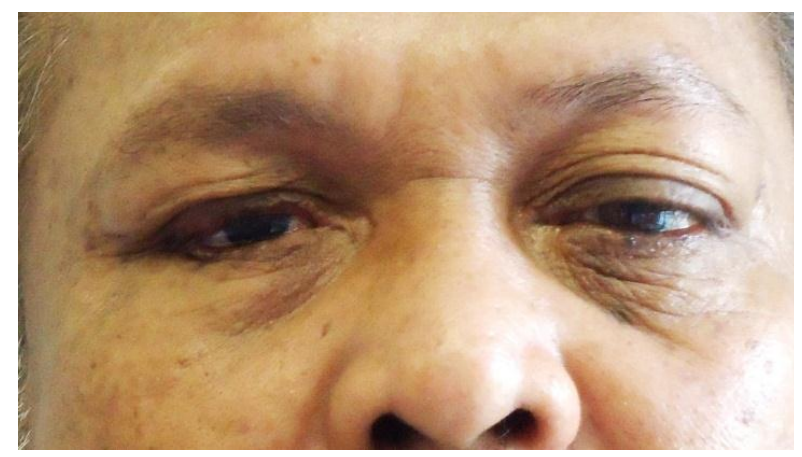

Gambar 7. Insersi Protesa Mata

\section{PEMBAHASAN}

Kehilangan bola mata merupakan proses yang traumatik baik secara medis maupun secara psikis. Permasalahan kehilangan bola mata dari sisi medis yaitu kesulitan dalam penglihatan. Dampak dari aspek psikologis adalah perasaan rendah diri (inferiority complex) serta penerimaan sosial yang berbeda dari sebelumnya. ${ }^{2,6,7}$

Perawatan ini menggunakan protesa mata non fabricated sebab protesa mata fabricated biasanya berasal dari Eropa atau Amerika (ras Caucasoid/ ras Negroid) sehingga tidak sesuai dengan kondisi anatomi mata orang Indonesia (ras Mongoloid). Faktor biaya juga menjadi pertimbangan karena harga pembuatan protesa mata fabricated di luar jangkauan sebagian besar masyarakat Indonesia sehingga protesa mata non fabricated menjadi alternatif perawatan. ${ }^{5}$

Trauma terjadi karena pasien mencoba melepas bola matanya, sehingga didapatkan diagnosa kehilangan bulbus oculi dextra akibat trauma. Pembuatan protesa mata non fabricated digunakan bahan resin akrilik. ${ }^{5}$ Keuntungan protesa mata non fabricated adalah warna protesa mata dapat disesuaikan dengan warna mata yang masih ada, harga lebih murah, dan secara anatomis dapat disesuaikan dengan soket mata pasien. Kerugian protesa ini adalah pembuatan protesa memerlukan waktu untuk proses di laboratorium. Kontraindikasi protesa ini adalah pasien yang alergi terhadap bahan akrilik dan kurangnya retensi soket mata. ${ }^{4}$ Pemilihan bahan akrilik (metil metakrilat) sebab memiliki adaptasi yang baik terhadap jaringan, estetika baik, awet, tidak mudah berubah warna, dapat dibentuk 
sesuai soket, harga ekonomis, dan mudah dalam manipulasi. ${ }^{3}$

Retensi, stabilisasi, dan kenyamanan protesa mata perlu dilakukan saat insersi. ${ }^{5}$ Kontrol dan evaluasi perubahan soket pada pemakaian protesa mata nonfabricated dilakukan 1 minggu setelah insersi. ${ }^{5}$ Pada pasien ini pergerakan protesa mata baik karena protesa mata dibuat mengikuti kontur soket mata. Dari sisi estetika protesa mata ini lebih baik karena pembuatan sklera dan pelukisan iris disesuaikan dengan mata sebelahnya. Protesa mata nonfabricated lebih dapat diterima pasien karena lebih sesuai dengan bentuk soket mata pasien dari pada protesa mata fabricated. ${ }^{2}$

Penggunaan fotografi sebagai bantuan dalam penentuan warna sklera sangat membantu proses pembuatan protesa mata. Fotografi mata asli pasien dapat mengurangi waktu perawatan pasien, karena biasanya pelukisan sklera dan iris dilakukan di depan pasien. ${ }^{6}$ Faktor yang perlu dipertimbangkan dalam menentukan lokasi iris adalah pada waktu terbuka biasanya kelopak mata atas menutupi setengah bagian dari iris, sedangkan batas bawah iris tepat atau sedikit di atas kelopak mata bawah. ${ }^{5}$

Keuntungan dari pembuatan protesa mata adalah dapat mengembalikan penampilan pasien mendekati mata normal. Dengan mengembalikan penampilan dapat meningkatkan kepercayaan diri pasien sehingga dapat diterima dalam kehidupan sosial bermasyarakat. Pemakaian protesa mata tidak dapat mengembalikan fungsi penglihatan pasien, akan tetapi dapat mengurangi trauma psikologis akibat kehilangan bola mata. ${ }^{8}$

\section{KESIMPULAN}

Pada pasien ini pergerakan protesa mata baik karena protesa mata dibuat mengikuti kontur soket mata. Dari sisi estetika protesa mata ini baik karena pembuatan sklera dan pelukisan iris disesuaikan dengan mata sebelahnya menggunakan bantuan fotografi mata pasien. Protesa mata nonfabricated lebih dapat diterima pasien karena lebih sesuai dengan bentuk soket mata pasien.

Kehilangan bola mata merupakan proses yang traumatik baik secara medis maupun secara psikis. Keuntungan dari pembuatan protesa mata adalah dapat mengembalikan penampilan pasien mendekati mata normal. Pembuatan protesa mata dapat mengurangi trauma psikologis akibat kehilangan bola mata. Dengan mengembalikan penampilan dapat meningkatkan kepercayaan diri pasien sehingga dapat diterima dalam kehidupan sosial bermasyarakat.

\section{DAFTAR PUSTAKA}

1. Pearce EC. Anatomi dan fisiologi untuk paramedis. Jakarta: Penerbit Gramedia Pustaka Utama, 2002. H. 314-322.

2. Deacon BS. Orbital implants and ocular prostheses: A comprehensive review www.jomtonline.com. Diunduh pada tanggal 25 April 2013.

3. Patil BA, Mankani NH, Chowdhary RE, Nagaraj. Rehabilitationof phthisis bulbi : A Case report. Journal of Clinical and Diagnostic Research. December 2011; Vol-5(8): 1679-1681.

4. Lubis S. Prothesis mata, laporan kasus. Jurnal Kedokteran Gigi Indonesia. 2005; 55: 433-36.

5. Rosalina C. Pembuatan obturator mata pada pasien dengan kehilangan mata akibat cacat bawaan. Majalah Kedokteran Gigi. 2010; Vol XVII: 41-44.

6. Dheeraj K, Ajay G, Hemant G, Gaurav C. Ocular prosthesis: a case report. Baba Farid University Dental Journal. 2010; Vol.1: 52-54.

7. Rahn A, Boucher LJ. Maxillofacial prosthetics: orbital and ocular prostheses. Philadelphia: W.B. Saunders Company; 1970. H. 151-168.

8. Adarsh N, Pradeep, Suresh BS, Yogesh RB, Rachana KB. Ocular prosthesis made easy: a case report. International Journal of Dental Clinics. 2011; Vol 3(1):105-106. 